\title{
4
}

\section{EL SERVICIO DE JUSTICIA PENAL SANTAFESINO: PRODUCCIŌN DE AUDIENCIAS ORALES, MARCO JURÍDICO Y ORGANIZACIÓN: EL CASO DE LA OFICINA DE GESTIÓN JUDICIAL DE LOS DISTRITOS JUDICIALES $N^{\circ} 1$ Y 2}

\author{
José Luis Longo Gasser ${ }^{(\bullet)}$ \\ Universidad Nacional del Litoral
}

\section{RESUMEN}

Obsenvar la modernización de los sistemas judiciales desde la óptica de la administración, lleva a la obtención de resultados que difícilmente se encuentren en la bibliografía jurídica. Nos planteamos estudiar el sistema penal santafesino, en el que se ha implementado un proceso adversarial, el cual se caracteriza por el desarrollo de audiencias, en las que las partes desenvuelven su rol de manera oral y, principalmente, el juez toma su decisión (resolución) en forma oral. A los fines de concretar cada una de las audiencias orales, el marco legal conformó una organización administrativa, separada de la jurisdiccional y dotada de funciones específicas, que apoyan y brindan soporte a los jueces en su labor. Analizar el número de recursos de los cuales se dispone y el grado de utilización que de los mismos se haga para celebrar

un determinado caudal de audiencias orales, nos permitirá conocer acerca del uso de los factores de producción involucrados en el proceso penal, que tiene como resultado el número total de audiencias celebradas. En nuestro estudio sobre la justicia penal santafesina, específicamente en las jurisdicciones de la sede Santa Fe y Rosario, para el período 2014 a 2018, hemos encontrado evidencia cuantitativa de una merma en la productividad media a mayor dotación de recursos, no obstante crecer la producción total de audiencias. Vale decir, que el incremento en el número de personal o la construcción de un mayor número de salas de audiencias, si bien inciden positivamente en la producción total, evidencia disminución en su rendimiento medio.

\section{PALABRAS CLAVE:}

adversarial, producción, penal, recursos, audiencia.

RECEPCIÓN: $24 / 05 / 20$

ACEPTACIÓN FINAL: 17/08/20 


\section{ABSTRACT}

Observing the modernization of judicial systems from the point of view of the administration leads to obtaining results that are difficult to find in the legal literature. We propose to study the Santa Fe penal system, in which an adversarial process has been implemented, which is characterized by the development of hearings, where the parties perform their role orally and, mainly, the judge makes his decision orally. In order to specify each of the oral hearings, the legal framework created an administrative organization, separate from the jurisdictional one and endowed with specific functions, which help and provide support to the judges in their work. Analyzing the number of resources that are available and the degree of use made of them to hold a certain volume of oral hearings, will allow us to know about the use of the production factors involved in the criminal process, which has as result is the total number of hearings held. In our study on criminal justice in Santa Fe, specifically in the jurisdictions of the Santa Fe and Rosario headquarters, for the period 2014 to 2018 , we have found quantitative evidence of a decrease in average productivity with greater resource allocation, despite growing production total audiences. In other words, the increase in the number of personnel or the construction of a greater number of courtrooms, although they positively affect total production, shows a decrease in their average performance.

\section{KEY WORDS:}

adversarial, production, resources, audience. 


\section{INTRODUCCIÓN}

Observar el funcionamiento de los sistemas penales argentinos actuales, donde su principal bandera de cambio es la oralidad e indagar en profundidad sobre sus características, la manera en que se han implementado y la composición de los recursos, nos posibilitará conocer mejor sobre los procesos de modernización judicial, la manera en que se presta el senvicio de justicia o cuando menos poder realizar una tarea comparativa entre sedes.

La provincia de Santa Fe ha implementado a partir del 10/02/2014 un sistema de enjuiciamiento penal adversarial, normado por ley 12.734 . Se realizó un giro pasando de un sistema inquisitorial cuya características principales eran: proceso escrito, secreto, concentración del poder en el juez (en las tareas de persecución, juzgamiento y administrador de su juzgado), labor ejercida por delegación y funcionamiento autónomo de los organismos jurisdiccionales; a un sistema adversarial basado en las siguientes características: oralidad a lo largo de todo el proceso, publicidad, participación y control ciudadano, división del poder del juez (ejercido ahora por otros actores), separación de las labores jurisdiccionales y administrativas y ausencia de funcionamiento de juzgados trabajando en formato estanco.

Las modificaciones introducidas al sistema procesal penal santafesino, provocaron un verdadero cambio organizacional, tomando como referencia dos 
factores que así lo indicarían: la modificación en la estructura de la organización y el proceso de aprendizaje y adaptación de sus miembros (Longo Gasser, 2018). Se estableció desde el ejecutivo provincial como mejor opción que su implementación se lleve delante de manera integral y en forma simultánea en todo el territorio provincial. A través del dictado del decreto $N^{\circ} 3811 / 2013$ que la provincia determinó que contaba con todo lo necesario para poner en funcionamiento el ordenamiento penal, en un todo de acuerdo con el marco legal sancionado, disponiendo de la provisión necesaria de los recursos materiales y financieros.

En línea con investigaciones de Binder, donde determinó "[que] no sea extraño que la tradición inquisitorial —una tradición de justicia sin litigio - se ensañe con el juicio y las audiencias orales" (Binder, 2013:180-181), hicieron mella en nuestro interés por indagar sobre la dimensión recursos y sobre la influencia de los mismos en la cantidad total de audiencias orales celebradas.

En lo particular rescatamos tres claves que se pueden abordar desde la administración y que el autor antes citado identifica en su trabajo: 1) la suspensión de las audiencias sin motivos de valía, 2) la falta de salas de audiencias disponibles, y 3) la falta de organización de todos los servicios auxiliares necesarios para el éxito de las audiencias.

Tomando como válida que la condición necesaria para alcanzar un desempeño eficaz es disponer de la capacidad institucional acorde, la que definimos aquí como "poseer la condición potencial o demostrada de lograr un objetivo o resultado a partir de la aplicación de determinados recursos» (Oszlak, 2014:1), partimos de la presunción que aquella organización que disponga de recursos suficientes, podrá alcanzar con mayor facilidad los objetivos planteados o, cuando menos, logrará mayores resultados, de aquella otra que no fuera provista con los recursos adecuados.

\section{ASPECTOS METODOLÓGICOS}

Mediante un diseño descriptivo-analítico describiremos la legislación a través la cual se le dio forma al sistema procesal penal, a continuación se detallará la estructura organizacional conformada, para finalmente recolectar información cuantitativa existente de las oficina de gestión judicial de los distritos judiciales $N^{\circ} 1$ y 2 .

El estudio del caso se hará mediante la introspección de datos existentes en el ámbito del fuero penal santafesino, indagaremos sobre la provisión y 
distribución de recursos en el período 2014-2018 de las Oficinas de Gestión Judicial de los Distritos Judiciales $N^{\circ} 1$ y 2, por último analizaremos la posible correlación de los mismos sobre la cantidad total de audiencias realizadas o celebradas. La recolección de información fue complementada con entrevista a los dos directores de oficina. Comparar ambas sedes, en términos de resultados finales alcanzados, atendiendo la cuantía de recursos con los que se conformó cada una de las oficinas, es otro de nuestros objetivos específicos. Los recursos (empleados y salas) serán observados como variable independiente y las audiencias realizadas la variable que depende del comportamiento de aquellos.

Nuestra hipótesis de trabajo se basa en suponer que, atento a la legislación sancionada y la nueva organización con que se conformó el sistema penal santafesino, la productividad de los recursos asignados a cada una de las oficinas de gestión judicial decrece ante cada nueva incorporación, no obstante continuar generando su respectivo aumento proporcional en la cantidad total de audiencias celebradas o realizadas.

Si bien el rendimiento de los factores de producción, en especial el personal, puede no ser estable o constante a lo largo del año e incluso presentar fuertes diferencia entre años, originado entre otros motivos en las propias capacidades, actitudes, aptitudes, licencias, etc., no está entre nuestros objetivos indagar sobre los aspectos cualitativos de este recurso, sin desconocer su importancia en el desarrollo de las actividades del sector público.

Dada la multiplicidad de actividades a ejecutar para concretar cada audiencia oral, tampoco se profundiza en la labor de los directores de cada oficina de gestión judicial, en relación al método implementado para distribuir al personal a las diferentes unidades internas, considerando que el tema exige una investigación en lo particular.

\section{LA PRODUCCIÓN DE AUDIENCIAS ORALES \\ EN EL SISTEMA PENAL ADVERSARIAL}

Un estudio del Programa de Naciones Unidas para el Desarrollo (PNUD, 2008), ha permitido apreciar que la debilidad estatal, entendida como crisis del Estado presente en el deficiente cumplimiento de las funciones que le son propias, sitúa a la justicia como institución que evidencia tales síntomas.

Emplearemos como marco conceptual que nos ayudará de guía en el estudio de la dinámica de funcionamiento del interior de la organización bajo análisis el modelo productivista planteado por Oszlak $\left(2004^{1}\right)$ e identificado como 
"sistema productivo", en el que específicamente empleando diferentes tipos de recursos, entre ellos humanos, materiales, financieros y tecnológicos - los que son obtenidos de su contexto- y realizando combinaciones diversas de los mismos se obtienen productos o servicios (resultado del proceso) utilizados para satisfacer necesidades de determinados valores, objetivos, expectativas y demandas sociales.

Consideramos correcto aclarar que, si bien, el sector público no es una "fábrica", en la que se introducen insumos y materias primas a un proceso que los transforma en un producto final, sí es factible realizar una extensión del concepto de sistema productivo (Las Heras, 2018:106), con el objetivo de analizar la forma en que opera el proceso decisional de transformación, dentro de una organización perteneciente a la administración pública (en nuestro caso el sector justicia).

En el caso del servicio de justicia brindado por la unidad organizacional bajo análisis, trabajaremos con los siguientes recursos o factores de producción: 1) recursos humanos: todos aquellos empleados, funcionarios y magistrados, 2) recursos materiales: principalmente constituido por las salas de audiencias y toda la instalación tecnológica necesaria para el funcionamiento de las mismas. En cuanto a la estructura, describiremos el fuero penal, como organización particular del Poder Judicial, en cuanto a la composición y diseño establecido en el marco legal vigente. Las normas están integradas por el conjunto de leyes que conforman el sistema adversarial, con más los reglamentos y regulaciones dictadas por la propia corte suprema de justicia.

El producto obtenido, por la organización a estudiar, no es el servicio de justicia como "algo abstracto", sino que, en este límite del estudio, nos focalizaremos en las audiencias celebradas o efectivamente realizadas. Esto es así ya que es una característica de las diferentes reparticiones que componen el Estado, el dedicarse prácticamente con exclusividad a la prestación de servicios con objetivos y estrategias muy específicas (Las Heras, 2006:24).

En el gráfico siguiente, se encuentra representada la relación de los diferentes factores involucrados en el proceso y cómo la naturaleza del marco normativo, los recursos empleados y el volumen y calidad de los mismos se transformarán en patrones de comportamiento que, a su vez, afectarán la magnitud de los productos obtenidos. 


\section{Gráfico 1.}

Sistema productivo fuero penal

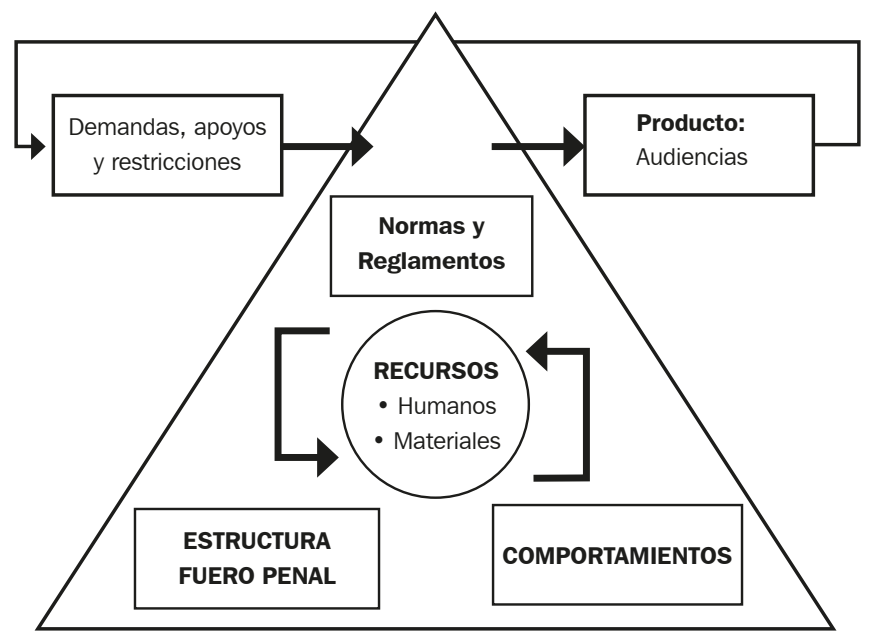

Fuente: adaptado de Oszlak 2004:9

Existe una dinámica que no es unívoca entre las distintas dimensiones y variables, sino que por el contrario la relación es multidireccional. A su vez, las combinaciones de los diferentes recursos utilizados en el proceso son afectados por las tres dimensiones (normas, estructuras y comportamiento), las que también resultan afectadas recíprocamente. La relación, bajo esta observación, termina siendo circular: normas $\leftrightarrow$ estructuras $\leftrightarrow$ comportamientos $\leftrightarrow$ normas.

Nos apoyaremos, principalmente, para el análisis realizado en nuestro trabajo, de terminología ${ }^{2}$ proveniente de la economía, así: productividad, representa la relación entre la cantidad total de producción obtenida y la cantidad empleada de los recursos o factores de producción necesarios para dicha producción. Tenemos así que, una actividad será más productiva cuantos menos recursos utilice para obtener la misma cantidad de producto final o, expresado de manera diferente, se obtenga un mayor número de producto final empleando la misma cantidad de factores de producción. Se emplean indistintamente aquí los términos "recursos" y "factores de producción".

Profundizando en el tema, destacamos que podemos obtener la productividad media dividiendo la cantidad total de producto obtenido, entre cada factor de producción (o recurso). Paralelamente, incorporamos lo que se conoce como 
productividad marginal, que es la que se obtiene de comparar cómo influye la incorporación de una nueva unidad de alguno de los factores de producción en la producción final, específicamente cuánto añade o quita a la producción total anexar una unidad de dicho recurso o factor.

En todo sistema productivo la productividad media y marginal crecerán a medida que incorporemos mayor número de unidades de factores de producción, siendo inicialmente la productividad marginal mayor que la media, hasta el momento en que ambas funciones se crucen marcando el punto en el cual, cada nueva unidad del factor de producción representará una merma en su contribución marginal, a partir de dicho momento y más allá que la producción total obtenida siga creciendo, la cuantía de dicho aumento será paulatinamente menor. Esto último, es lo que en economía recibe el nombre de ley de rendimientos decreciente.

A nuestro entender, subyace al modelo productivista descripto el concepto de capacidad institucional, definida como la habilidad de las organizaciones del Estado para absorber responsabilidades, operar más eficientemente y fortalecer las rendiciones de cuentas (Rosas Huerta, 2008:123), vale decir la habilidad para lograr un propósito, específicamente aquel para el cual la organización fue pensada y diseñada. Hilderbrand y Grindle identifican cinco dimensiones mediante las cuales se afectan tanto las capacidades del sector público como las intervenciones para construirlas, de las cuales extraemos particularmente dos de ellas: 1) los recursos humanos dentro de la cada organización y 2) la organización misma (Isuani, 2012:55).

Es precisamente el cambio en el sistema de enjuiciamiento penal de la provincia de Santa $\mathrm{Fe}$, donde nos detendremos en nuestro estudio tanto en su estructura, las normas que lo conforman y, especialmente, la dotación de personal con que fueron conformadas las oficinas de gestión judicial de primera instancia del distrito judicial $N^{\circ} 1$ y 2 , y poder determinar si el producto final (audiencias celebradas) obtenido está acorde con la cantidad de empleados, funcionarios y magistrados.

El nuevo proceso penal santafesino es regido por la ley 12.734, mediante la cual se ha establecido la oralidad, la contradicción y la publicidad como los principios fundamentales a ser observados. El 10/02/2014 marcó el día en que se realizó, en la práctica, el cambio de sistema de enjuiciamiento santafesino, pasando de un sistema inquisitivo a otro de características adversarial. Como labor legislativa previa a la puesta en funcionamiento del nuevo ordenamiento, se realizó la sanción del paquete de leyes que dieron forma al sistema de enjuiciamiento penal de la provincia de Santa Fe. 
La modificación normativa, ha traído como una de sus principales innovaciones un cambio en la organización del fuero penal, implementando una estructura nueva, diferente al modelo preexistente de características estanco, conservador, reservado y aislado de la sociedad, lo que indudablemente requiere de empleados, funcionarios y magistrados con una visión amplia, abierta, transparente y que actúen con un mayor compromiso de cara a la sociedad, o cuando menos con una impronta diferente a la mostrada en el ciclo previo.

La nueva estructura organizacional, fue dispuesta primariamente por la ley 13.018 y en lo particular la corte suprema de justicia mediante el dictado del reglamento provincial de oficinas de gestión judicial de Santa Fe, le dio forma a la nueva dependencia judicial, que tiene encomendada las labores administrativas del fuero penal.

\section{SISTEMA ADVERSARIAL: CARACTERÍSTICAS PRINCIPALES}

Denominado indistintamente como sistema acusatorio o adversarial ${ }^{3}$, se caracteriza principalmente por "la división de los poderes ejercidos en el proceso, por un lado, el acusador, quien persigue penalmente y ejerce el poder requirente, por el otro, el imputado, quien puede resistir la imputación, ejerciendo el derecho de defenderse, y, finalmente, el tribunal, que tiene en sus manos el poder de decidirn (Maier, 1996) ${ }^{4}$.

Esta conceptualización, resalta el rol de los principales actores que se encuentran presentes en el proceso y refleja la acción de un tribunal que actúa como árbitro, entre acusador y acusado que se enfrentan — jurídicamente hablando-, en pos de alcanzar el triunfo de sus intereses, todo lo cual se da en un debate público, oral, continuo y contradictorio. La oralidad a lo largo de todo el proceso es lo que otorga un tinte distintivo al sistema.

Como se dijo, la labor desarrollada por las partes se lleva adelante en un ámbito público, esto es, ante la mirada de terceros, ajenos incluso al proceso que se sustancia, que actúan como verdaderos veedores de la labor desempeñada por los actores, propiciando así la participación y control de la ciudadanía.

El rol de la persecución penal recae sobre el fiscal, y el juez ve limitado su accionar a la actuación específica de juzgar. Esta división de funciones limita el accionar del juez a uresolver litigios durante las etapas preparatorias, controlar que la preparación del caso o las investigaciones no afecten derechos (...) o juzgar el caso, preservando lo estrictamente jurisdiccional» (Binder, 2013:34).

En el aspecto administrativo, los sistemas adversariales encomiendan las 
tareas de soporte y apoyo a un colaborador del juez (Palma, 2017:165) —tanto estratégicas como operativas- a funcionarios dedicados y profesionalizados. Así, estos administradores ${ }^{5}$ se abocan a la realización de esas labores mediante la asistencia del personal a su cargo, sin tener injerencias cruzadas entre área jurisdiccional y área administrativa.

Serán estos funcionarios los que tomarán las decisiones sobre la provisión, manejo y disposición de los recursos —-materiales y humanos-, y también estarán entre sus competencias las de organizar agenda, mantener canales de comunicación con el resto de las instituciones, elaborar soluciones que faciliten la operatoria de los magistrados, entre otras.

En los sistemas procesales de tipo adversarial, los jueces ejercerán exclusivamente su labor jurisdiccional y de manera paralela se estructura una organización que hará las labores administrativas necesarias que sirvan de apoyo al servicio de justicia dentro del fuero, en forma directa hacia los jueces e inmediata hacia el resto de los actores.

\section{MARCO JURÍdiCO DEL NUEVO SISTEMA ADVERSARIAL SANTAFESINO}

La Ley No 12.734 (nuevo código procesal penal - CPP) es la que articula el nuevo proceso penal santafesino; en el aspecto jurídico, establece la oralidad, la contradicción y la publicidad como los principios fundamentales a ser observados. Determina la totalidad de los mecanismos y herramientas de los que disponen las partes para desenvolverse en su actuación en el ámbito de sus funciones.

Específicamente, algo que es de nuestro interés resaltar, el artículo 49 establece la creación de la "Oficina de Gestión Judicial" (OGJ) como nuevo estamento, con responsabilidad exclusiva de las actividades administrativas.

La ley No 13.018 "Organización de los Tribunales Penales»: establece la conformación de trabajo del área jurisdiccional —Colegio de jueces- y del nuevo estamento encargado de las labores administrativas dentro del fuero penal, vale decir la oficina de gestión judicial, asimismo regula la forma y manera de vincularse entre ambas áreas. A lo largo del presente trabajo se hará amplia referencia a su contenido y se analizarán aquellas partes de mayor interés para nuestros objetivos.

Luego de la puesta en funcionamiento del nuevo sistema adversarial, se sancionaron las siguientes leyes, muchas de las cuales se establecieron para realizar pequeñas modificaciones que solucionaban inconvenientes prácticos 
advertidos por el conjunto de los actores, y en otras, la sanción de la ley buscó finalizar la etapa de transición y, en las más recientes, ampliar las competencias materiales del nuevo sistema.

Así la ley No 13.405 "Ley de Herramientas para el Sistema Penal»: es importante remarcar que su sanción se produjo a pocos días de la puesta en funcionamiento del nuevo sistema adversarial, y por su intermedio se intentó salvar cuestiones prácticas que los diferentes actores visualizaron momentos previos al inicio del proceso penal. A nuestros intereses resaltamos las modificaciones introducidas tanto al código procesal penal - ley 12.734- como a la ley que regula el funcionamiento del nuevo fuero penal - ley 13.018 - destacando:

a) modificación en los plazos que transcurre desde la privación de libertad de la persona imputada hasta la realización de audiencia imputativa y de prisión preventiva, el texto original establecía un máximo de 48 horas para la realización de ambas audiencia —o en una única audiencia-, pasando con la reforma a un plazo de 96 horas en total (48 horas para audiencia imputativa y 48 horas posteriores para audiencia de prisión preventiva).

b) notificaciones por medios electrónicos, reemplazando la cédula judicial en formato papel, a los fines de brindar mayor agilidad al proceso de notificaciones emanada desde la oficina de gestión judicial.

Por otro lado, la ley № 13.746, modifica 56 artículos del código procesal penal y cambios menores en la ley 13.013, entre los principales.

a) Las correcciones a la ley 12.734 tuvieron en miras en agilizar principalmente la labor de los representantes del Ministerio Público de la Acusación, sea dándoles mayores herramientas para la toma de decisión que faciliten la conclusión ágil y rápida de las causas que así lo consideren necesarios dentro del ámbito del propio ministerio sin intervención jurisdiccional, ofreciendo métodos más directos de resolución de conflictos.

b) Así mismo se legislan los "derechos de las víctimas", lo que implica que deben ser notificadas e informadas de la marcha del proceso, dándole la posibilidad de ser escuchadas por un juez en audiencia oral en caso de ser su voluntad, previo a que el magistrado adopte alguna resolución que se vincule al cambio de la situación procesal del imputado o ante el dictado de sentencias. c) Se intenta agilizar el trámite de la constitución de querellante en una causa, posibilitando arribar a una resolución de admisión de manera más rápida, si no hubiera contradicción entre las partes sobre dicha pretensión. d) Nuevamente se modifican los plazos para el desarrollo de audiencia imputativa y de prisión preventiva, pasando del esquema anterior a un nuevo 
plazo de 72 horas desde el momento en que se lo priva de su libertad al imputado, prorrogable jurisdiccionalmente por 24 horas $^{6}$.

e) Se acortan los plazos de los que dispone la oficina de gestión judicial para preparar el juicio oral, disponiéndose que en 48 horas de la resolución de elevación a juicio la oficina sorteará tribunal, el que al quedar firme se procederá a fijar día y hora de inicio de audiencia de debate la que no podrá ser antes de los 10 días y no podrá ser superior a los 30 días.

\section{ESTRUCTURA ORGANIZACIONAL DEL SISTEMA ADVERSARIAL SANTAFESINO}

La ley 13.018 que le da ordenamiento al fuero penal, es de suma trascendencia ya que fija los parámetros fundamentales que distinguen su organización bajo el sistema adversarial, la que resulta muy diferente de como se encontraba integrada bajo el sistema inquisitivo.

En materia jurídica, fija principios de actuación que deberán ser observados por los magistrados al momento de ejercer sus funciones: resalta que sus labores son indelegables, los limita a la realización de tareas jurisdiccionales — excluyéndolos de toda labor administrativa -, refiere a la imparcialidad e independencia con que deben actuar, les asigna responsabilidad para garantizar el cumplimiento de los principios de oralidad, publicidad, simplicidad y celeridad, y los obliga a estar presentes en forma ininterrumpida durante la celebración de las audiencias.

La corte suprema de justicia tuvo bajo su responsabilidad la reglamentación - acta acuerdo $N^{\circ} 41 / 2013$ - mediante la cual se completó la estructura del nuevo estamento del fuero penal, inexistente en el resto de la estructura del sistema judicial santafesino, y por lo tanto sancionó así el reglamento único de oficina de gestión judicial de la provincia de Santa Fe. A través de su implementación, el poder judicial fijó la organización interna de la nueva dependencia, que resulta de suma importancia para el funcionamiento del sistema adversarial puesto que es esta oficina la encargada de, entre otras tareas que trataremos con mayor detalle seguidamente, brindar soporte y apoyo al área jurisdiccional, gestionar los recursos y organizar la agenda de audiencias. 


\section{LA OFICINA DE GESTIÓN JUDICIAL}

Un sistema de enjuiciamiento distinto requiere de una organización completamente diferente, razón por la cual el legislador santafesino introdujo reformas innovadoras en la normativa que potenciaron el proceso de implementación buscado. Principalmente la Ley № 13.018 incluyó tales cambios, entre los que destacaremos como eje la separación de dos áreas: la jurisdiccional (colegio de jueces) y la administrativa (oficina de gestión judicial), bien delimitadas en sus funciones - definidas exprofesamente en los dos primeros artículos.

Tanto las dos áreas como las relaciones existentes en el nuevo sistema penal, se encuentran representadas en el Gráfico 2.

Como se pude apreciar la labor jurisdiccional (lado izquierdo del gráfico) se encuentra aglutinada en los respectivos colegios de jueces (de primera y de segunda instancia) y la tarea administrativa es desarrollada por las oficinas de gestión judicial de 1ra. y 2da. instancia (lado derecho del gráfico).

\section{Gráfico 2.}

Estructura organizacional fuero penal santafesino

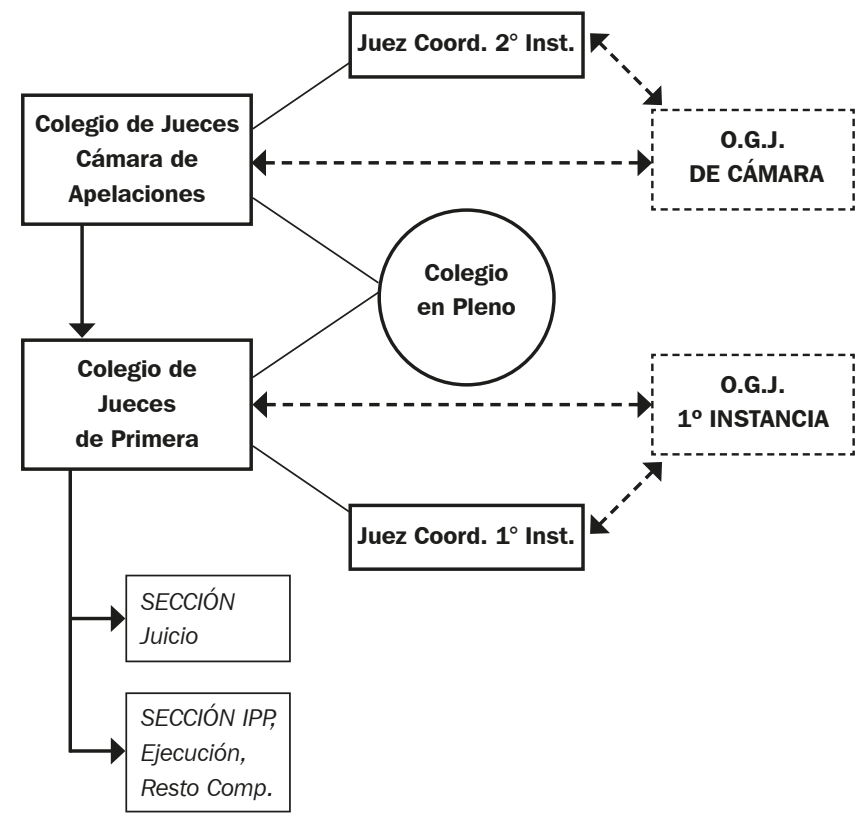

Fuente: elaboración propia en base a Ley 13.018. 


\subsection{DISTRIBUCIÓN GEOGRÁFICA}

La ley 13.018 en su artículo 30 crea la oficina de gestión judicial a la cual le asigna con exclusividad la realización de la totalidad de las labores administrativas, integrando una oficina en cada distrito judicial donde existiera un colegio de jueces, tanto de primera como de segunda instancia, cuya distribución geográfica en el ámbito de la provincia de Santa Fe es la que se ve en la Tabla 1.

Nos centraremos particularmente en la primer y segunda circunscripción. En la circunscripción judicial № 1 se conformó una oficina de gestión judicial de primer instancia con competencia en el distrito judicial $\mathrm{N}^{\circ} 1$ y una oficina de segunda instancia que además de brindar apoyo al colegio de jueces de segunda instancia de la circunscripción se encuentra a cargo de la oficina de primera instancia del distrito judicial $N^{\circ} 11$ - San Jorge-.

Situación similar se observa en la circunscripción judicial № 2 en la que se ha establecido una oficina de gestión judicial de primera instancia con competencia en el distrito judicial $N^{\circ} 2$ y una oficina de segunda instancia que además de ser el soporte administrativo del colegio de jueces de segunda instancia de dicha circunscripción tiene a su cargo la responsabilidad de las oficinas de primera instancia con competencia en los distrito judiciales $N^{\circ} 6$ - Cañada de Gomez-, $\mathrm{N}^{\circ} 7$ - Casilda-, № 12 -San Lorenzo-, y No 14 -Villa Constitución-. El motivo de la separación de oficinas por instancia, en los distritos $N^{\circ} 1$ y 2 , se debe a la exigencia legal que establece que en aquellos distritos en los que existe un colegio de jueces de primera instancia deberá integrarse con una oficina de gestión judicial, situación que se presenta únicamente en dichos distritos.

En cuanto a las oficinas de las circunscripciones judiciales $N^{\circ} 3,4$ y 5 organizan labores conjunta de primera y segunda instancia, atento a que en el interior de sus distritos judiciales no se cuenta con el número suficiente de Jueces para formar un colegio de jueces de primera instancia, requisito establecido en la norma vigente. 
Tabla 1.

Distribución de las Oficinas de Gestión Judicial

\begin{tabular}{|c|c|c|}
\hline Circunscripción & Oficinas de Gestión Judicial & \\
\hline Circ. Judicial $N^{\circ} 1$ - Santa Fe & $\begin{array}{l}\text { Oficina de Gestión Judicial } \\
\text { Primera instancia distrito judicial } N^{\circ} 1\end{array}$ & $\begin{array}{l}\text { Oficina de Gestión Judicial } \\
\text { Segunda Instancia }\end{array}$ \\
\hline Circ. Judicial N ${ }^{\circ} 2$ - Rosario & $\begin{array}{l}\text { Oficina de Gestión Judicial } \\
\text { Primera instancia distrito judicial } N^{\circ} 2\end{array}$ & $\begin{array}{l}\text { Oficina de Gestión Judicial } \\
\text { Segunda Instancia }\end{array}$ \\
\hline Circ. Judicial $N^{\circ} 3$ - Venado Tuerto & \multicolumn{2}{|c|}{ Oficina de Gestión Judicial de Primera y Segunda Instancia } \\
\hline Circ. Judicial $N^{\circ} 4-$ Vera & \multicolumn{2}{|c|}{ Oficina de Gestión Judicial de Primera y Segunda Instancia } \\
\hline Circ. Judicial $N^{\circ} 5$ - Rafaela & \multicolumn{2}{|c|}{ Oficina de Gestión Judicial de Primera y Segunda Instancia } \\
\hline
\end{tabular}

Fuente: elaboración en base a Ley 13.018

7.2 PRINCIPIOS Y CRITERIOS DE ACTUACIÓN DE LAS OFICINAS DE GEST IÓN JUDICIAL Como soporte y apoyo a la actividad jurisdiccional, la ley 13.018 en su artículo 31 le fija los siguientes principios a su estructura: jerárquica, división de funciones, coordinación y control.

Debiendo actuar con los siguientes criterios:

- Agilidad

- Deformalización.

- Eficacia.

- Eficiencia.

- Racionalidad del trabajo

- Responsabilidad por la gestión

- Coordinación y cooperación entre administradores

\subsection{FUNCIONES Y ATRIBUCIONES}

Se han establecido las funciones de la oficina diferenciándose entre las concernientes al director y las que corresponden a los funcionarios que la integran, así:

a) Funciones del Director:

- Dirigir la Oficina de Gestión Judicial, siendo el responsable de todas sus áreas. 
- Decidir en relación al personal.

- Mantener el suministro de insumos necesarios.

- Coordinar con los directores de las otras oficinas de gestión judicial.

- Controlar y evaluar la gestión administrativa y financiera.

b) Funciones de los Funcionarios:

- Organizar la agenda

- Garantizar la eficacia y autenticidad de las registraciones de audiencias

- Planificar y publicar la lista de audiencias.

- Garantizar que se provean todos los materiales necesarios para la realización de audiencias

- Evaluar y programar audiencias inmediatas.

- Realizar las gestiones necesarias para garantizar que las audiencias programadas se desarrollen con normalidad.

- Extender certificaciones y constancias

c) Atribuciones de la Oficina de Gestión Judicial:

- Distribución equitativa del trabajo de los jueces.

- Asistir administrativamente a los jueces

- Dar información a las partes

- Apoyar materialmente a los jueces y a las partes durante el desarrollo de las audiencias.

- Elaborar la agenda semanal y mensual del despacho judicial

- Recibir y registrar los requerimientos de audiencias.

- Custodiar, iniciar o mantener la cadena de custodia sobre los elementos probatorios.

- Comunicar a los jueces del requerimiento de las audiencias.

- Convocar a los sujetos procesales y demás personas a las audiencias.

- Realizar los recordatorios necesarios a los sujetos procesales.

- Realizar las comunicaciones necesarias, tanto interna como externa.

- Llevar la agenda de las audiencias.

- Confeccionar una carpeta judicial, para cada caso, a los efectos de registrar las decisiones jurisdiccionales que se dicten. Ello bajo criterios de desformalización.

- Actualizar registros de abogados, fiscales, defensores y demás actores.

- Actualizar y depurar registro de comunicaciones.

- Registrar audiencias y resoluciones y sentencias, y proceder a su resguardo.

- Garantizar y asegurar la inalterabilidad de los registros. 
- Controlar oportunamente los testigos, peritos y demás personas que deban asistir a las audiencias.

- Efectuar un seguimiento permanente del desarrollo del colegio de jueces y su funcionamiento cualitativa y cuantitativamente.

\subsection{ESTRUCTURA DE LA OFICINA DE GESTIÓN JUDICIAL}

A continuación procedemos a detallar específicamente las funciones que desarrolla cada área dentro de la oficina de gestión judicial, en base al reglamento único de oficinas de gestión judicial de la provincia de Santa Fe, establecido por la corte suprema de justicia por acuerdo de ministros acta $N^{\circ} 41 / 2013$. Mediante la reglamentación se dio forma a la estructura que dividió la oficina en dos subdirecciones, una jurisdiccional y otra administrativa, organización funcional que se representará gráficamente más adelante. La primera eminentemente abocada a todas las labores que den soporte y apoyo a la tarea jurisdiccional de manera directa y la subdirección administrativa encargada de afianzar las tareas de la propia oficina.

a) Dirección oficina de gestión judicial:

El director es el responsable máximo de la gestión administrativa.

Tiene a su cargo implementar en su colegio de jueces la política de gestión que garantice estándares de calidad y eficiencia en el senvicio judicial, existiendo entre sus principales atribuciones y responsabilidades: a) proponer los criterios de gestión y la distribución del personal para asistir a la función jurisdiccional de los Jueces, b) procurar la unificación de los criterios de actuación entre los colegios de jueces y la oficina de gestión judicial, a fin de coordinar y elaborar prácticas de apoyo administrativo al trabajo jurisdiccional que sean comunes para todos los jueces, propendiendo a la estandarización de procesos y c) garantizar la asignación y distribución de las carpetas judiciales y requerimientos jurisdiccionales a los Jueces, contemplando una carga de trabajo razonable y equitativa.

\section{b) Sub-Direcciones:}

La creación de la figura de los sub-directores tiene por finalidad principal la de encargarse de asesorar al director en materia de sus incumbencias profesionales, hacer ejecutar las tareas asignadas a las unidades internas que de cada uno de ellos dependen y reemplazar a aquel cuando fuera necesario asumiendo las atribuciones del cargo. A continuación se tratarán cada una de las unidades internas de la oficina de gestión judicial, de acuerdo al diseño 
organizacional dispuesto en la reglamentación vigente, en primer término se desplegará la conformación de la Sub-Dirección Jurisdiccional (Tabla 2) y en segundo lugar la Sub-Dirección de Administración (Tabla 3).

Seguidamente presentamos en un gráfico la totalidad de la organización que posee toda oficina de gestión judicial de la provincia de Santa Fe, indicando la dependencia, las relaciones y los nombres de cada unidad interna (Gráfico 3).

\section{Tabla 2.}

Unidades Internas de la Sub-Dirección Jurisdiccional

\begin{tabular}{|c|c|}
\hline Unidad interna & Funciones \\
\hline $\begin{array}{l}\text { Unidad de Atención } \\
\text { al Público }\end{array}$ & $\begin{array}{l}\text { - Brindar adecuada atención a personas particulares y/o profesionales } \\
\text { que concurran personalmente a la oficina. } \\
\text { - Vincular las presentaciones de las partes con la carpeta judicial } \\
\text { respectiva. }\end{array}$ \\
\hline $\begin{array}{l}\text { Unidad de Administración } \\
\text { de Causa }\end{array}$ & $\begin{array}{l}\text { - Coordinar actividades de agenda y despacho diario. } \\
\text { - Realizar las actividades relacionadas con el apoyo a los magistrados. }\end{array}$ \\
\hline $\begin{array}{l}\text { Unidad de Notificaciones } \\
\text { y Comunicaciones }\end{array}$ & $\begin{array}{l}\text { - Realizar las actividades de notificación de disposiciones jurisdicciona- } \\
\text { les y administrativas. } \\
\text { - Efectuar las comunicaciones de las disposiciones jurisdiccionales. }\end{array}$ \\
\hline Unidad de sala & - Llevar adelante las audiencias orales. \\
\hline $\begin{array}{l}\text { Unidad de Control de } \\
\text { Condena Condicional }\end{array}$ & $\begin{array}{l}\text { - Efectuar el soporte necesario para el correcto desarrollo del control } \\
\text { de las condenas condicionales. }\end{array}$ \\
\hline $\begin{array}{l}\text { Unidad de Control Efectivo } \\
\text { de Pena }\end{array}$ & $\begin{array}{l}\text { - Efectuar el soporte necesario para el correcto desarrollo del control } \\
\text { de las condenas con pena efectiva. }\end{array}$ \\
\hline
\end{tabular}

Fuente: elaboración propia. 
Tabla 3.

Unidades Internas de la Sub-Dirección Administrativa

\begin{tabular}{ll}
\hline Unidad interna & Funciones \\
\hline Unidad de Informática & $\begin{array}{l}\text { - Proveer el soporte técnico interno necesario. } \\
\text { • Controlar el buen funcionamiento del equipamiento } \\
\text { tecnológico de la dependencia. }\end{array}$ \\
\hline Unidad de Recursos, Estadísticas & $\begin{array}{l}\text { - Elaborar las estadísticas de la oficina. } \\
\text { y Servicios }\end{array}$ \\
$\begin{array}{ll}\text { - Gestión de los recursos humanos de la dependencia. } \\
\text { el funcionamiento de la dependencia. }\end{array}$ \\
\hline Unidad Financiera & $\begin{array}{l}\text { - Controlar y evaluar la gestión administrativa y financiera. } \\
\text { Unidad de Elementos Probatorios }\end{array}$ \\
\hline
\end{tabular}

Fuente: elaboración propia. 


\section{Gráfico 3.}

Organigrama OGJ

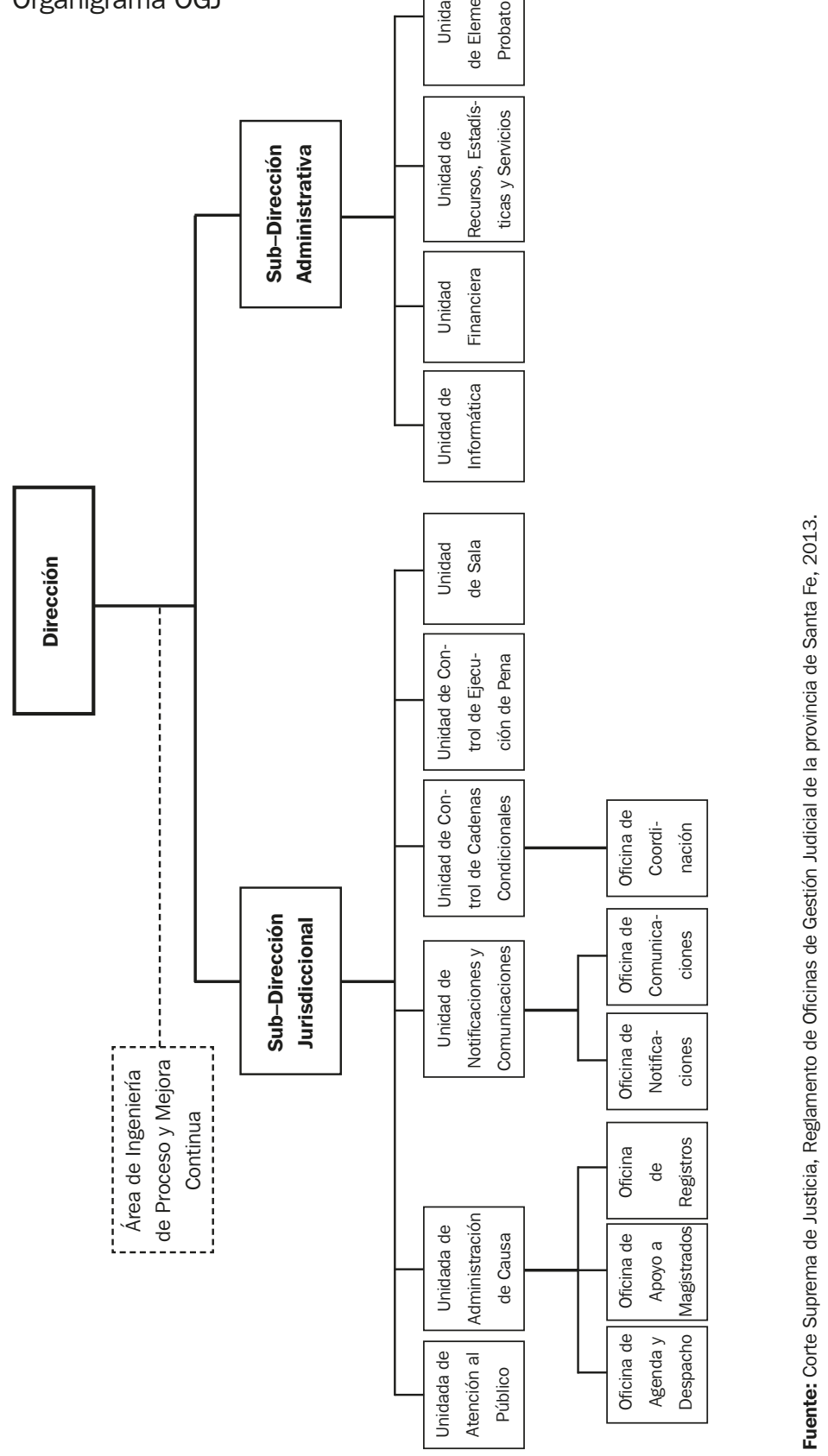




\subsection{VÍNCULO CON EL COLEGIO DE JUECES}

Con anterioridad se exhibió la conformación del nuevo fuero penal santafesino, allí se graficaron las relaciones de dependencia que existen entre las nuevas figuras y se muestra el vínculo existente entre los colegios de jueces con su respectiva oficina de gestión judicial.

En el primer artículo de la Ley 13.018 se establece específicamente que la labor de los jueces se limita al cumplimiento de sus funciones jurisdiccional, las cuales deben ser realizadas sin delegar en empleados y/o funcionarios de la oficina de gestión judicial.

En el segundo artículo de dicha ley, se establece que los colegios se regirán por los principios de flexibilidad de su estructura organizativa y de rotación de todos sus integrantes. En tanto, el área administrativa es responsable por las labores que les son propias, no teniendo competencia en las decisiones jurisdiccionales.

A continuación describiremos los detalles más importantes desde la administración, que hacen al funcionamiento de los colegios de jueces de primera instancia ${ }^{7}$.

a) Colegio de Jueces primera instancia:

Este colegio y en atención a las labores jurisdiccionales a las que se encuentran abocados sus integrantes, de acuerdo a la normativa vigente se divide en: 1) sección de juicio oral y 2) sección de investigación penal preparatoria, ejecución y demás competencias. A esta última, dado el cambio normativo del año 2018, se incluye las contravenciones (antigua competencia de los juzgados de faltas provinciales).

La división del trabajo establece que las secciones en que se separa el colegio será objeto de un sorteo anual entre los magistrados que lo integran, estableciéndose el número necesario de jueces que compondrán cada una de ellas de acuerdo a necesidades de servicio, dando garantía a la rotación de los integrantes en ambas secciones. Todo lo cual deberá respetar una equitativa distribución de las tareas.

En aquellos casos en los que existen más de un juez por sección se deberá determinar los turnos en los que intervendrá cada uno.

En todos los casos la legislación remarca claramente que la intervención de los diferentes magistrados en las dos secciones en que se conforma el colegio de jueces se basará en una reglamentación. Así mismo, la norma refiere en su artículo 25, que se «podrá modificar la distribución, funciones y asignación de los casos dentro de cada colegio, en virtud del principio de flexibilización organizativa, siempre que se respete el de rotación y garantice el acceso a la justician. El funcionamiento de cada colegio de jueces está exento de mayor complejidad. 


\section{b) Colegio en pleno:}

Es una integración que el legislador ha formalizado para lograr la participación de la totalidad de los magistrados de una misma circunscripción judicial, tanto de primera como de segunda instancia, para desarrollar las siguientes funciones: elaborar y ejecutar la política administrativa de la justicia penal, dictar su propio reglamento y realizar reuniones periódicas con representantes del MPA, SPPDP para coordinar actividades interinstitucionales. La legislación le impone el deber de reunirse semestralmente. En un principio, la normativa le confería cierta ascendencia de control sobre la oficina de gestión judicial, siendo posteriormente eliminado con la sanción de la ley 13.699 tratada anteriormente.

Cada colegio en pleno tendrá autoridades que surgen del seno de los colegios de primera y segunda instancia, tal designación será por período anual y saldrá de una elección en reunión plenaria. Así ejercerá como presidente el juez elegido del conjunto de magistrados de segunda instancia y como vicepresidente el magistrado votado entre los magistrados de primera instancia. Presidente y vice ejercerán la representación protocolar del fuero penal de su circunscripción, debiendo presentar un informe relativo a la gestión, los resultados de la actividad jurisdiccional, los recursos con los que cuentan, la relación con los demás actores del proceso, todo previa aprobación del colegio en pleno correspondiente.

\section{c) Juez Coordinador:}

Dado que para la organización del área jurisdiccional se ha conformado un colegio de jueces que guarda las características anteriormente detallada, y dada la integración de un área administrativa que le brinda soporte y apoyo a la jurisdicción, se hizo necesaria la designación de un responsable del colegio que actué en representación del conjunto de los jueces, denominando al mismo juez coordinador, a los fines fundamentalmente de: coordinar labores intracolegio, unificar criterios de actuación con la oficina de gestión judicial y elaborar un informe anual sobre el resultado de la gestión y eficacia del servicio para presentar al colegio en pleno.

En cada colegio de jueces, tanto de primera como de segunda instancia, se debe elegir el magistrado que actuará como coordinador, actividad que se desarrolla en períodos anuales. Atento a la actividad de coordinación que desarrollará el magistrado elegido, la oficina de gestión judicial debe considerar dicha función al momento de realizar la distribución del trabajo a los diferentes magistrados del colegio. 


\section{PRODUCCIÓN DE AUDIENCIAS}

Hemos señalado que el sistema adversarial tiene entre sus principales objetivos, que las decisiones jurisdiccionales sean dictadas en forma oral y que las mismas sean parte indisoluble durante el desarrollo de las audiencias. A fin de alcanzar una resolución —condenatoria o absolutoria - en un juicio oral, el proceso penal debe transitar necesaria e indefectiblemente por una serie de etapas claramente establecidas en el código procesal penal, las cuales se materializan en audiencias. Es condición necesaria la participación de las partes en cada audiencia, específicamente: fiscal, defensa técnica, querellante y su representante si lo hubiera, imputado y magistrado, permite, así, dar cumplimiento a las garantías constitucionales establecidas en la carta magna nacional y provincial.

8.1 FUNCIONES DE LA OFICINA DE GEST IÓN JUDICIAL EN LA PRODUCC IÓN DE AUDIENCIAS

Entre las múltiples actividades que posee asignada la oficina de gestión judicial figuran las tareas propias de recepción de solicitudes, de agendamiento de la totalidad de las audiencias, así también del proceso de hacer saber a las partes de las mismas y por último, la celebración propiamente dicha de la audiencia.

Ante cada solicitud que marque controversia entre las partes, será necesaria la realización de una audiencia oral. A tal fin, la ley obliga y responsabiliza a la oficina para que por intermedio de sus unidades internas proceda a la organización, notificación y realización de audiencias.

Específicamente el artículo 31 de la ley 13.018 describe que, entre las atribuciones, tiene a su cargo «recibir y registrar los requerimientos de audiencia», como así también "elaborar la agenda semanal y mensual».

La primera de las labores se concreta relacionando cada solicitud a la carpeta judicial respectiva.

La reglamentación de oficina de gestión judicial establece, para el cumplimiento del agendamiento, las siguientes tareas: i) determinar el tipo de audiencia, ii) establecer las partes que participarán en la misma, iii) designar el tribunal — de acuerdo a una distribución equitativa de trabajo-, iv) fijar día y hora de audiencia, v) establecer su duración, vi) determinar la sala de audiencia a emplear, entre las principales.

Finalizada la tarea de agendamiento de la audiencia, se deberá cumplir con el requisito de notificación a las partes, convocando a los sujetos necesarios y dar publicidad de las mismas.

La legislación establece "convocar a los sujetos procesales y demás personas a la audiencia», "realizar los recordatorios necesarios a los sujetos procesales 
para garantizar el éxito de la audiencia", y "realizar las comunicaciones necesarias". En lo referente al conjunto de tareas que la reglamentación dispuso, se destacan: i) notificar las audiencias programadas, ii) hacer recordatorios a través de medios eficaces disponibles para que las audiencias no se frustren, iii) confirmar la efectiva recepción de notificación, iv) solicitar y coordinar el traslado de los detenidos y v) emitir las citaciones necesarias. Paralelamente deberá llevar registros de fiscales, defensores públicos y privados, a los fines de facilitar las comunicaciones.

La labor siguiente será, en la fecha y hora fijada, la celebración de la audiencia organizada, identificando como tareas necesarias a: i) disposición de sala de audiencias de acuerdo a lo previsto, ii) asistencia en tiempo y forma de las partes, iii) dar inicio a la grabación de la audiencia, iv) confección de acta con la correspondiente decisión jurisdiccional y v) resguardar la información generada.

Es preciso remarcar que para la celebración o realización de cada audiencia, la presencia de los siguientes sujetos, es condición indispensable: juez, fiscal, defensor (público o privado), imputado y representante de la querella -en caso de haber sido aceptados en este rol.

Seguidamente, y a los fines de ordenar nuestro análisis, separaremos en tres etapas 1) investigación penal preparatoria, 2) juicio y 3) ejecución, el conjunto de audiencias factibles a desarrollarse en un proceso penal, desde su inicio y hasta la culminación del pleito, remarcando que existen otros muchos tipos de audiencias que a los fines del presente trabajo su estudio y análisis no adquieren mayor trascendencia. En todos los casos que enumeramos, la oficina deberá cumplir, obligada y necesariamente, con el mecanismo de organización de audiencias detallado. 


\section{Tabla 4.}

Tipos de audiencias por etapa procesal

\begin{tabular}{lll}
\hline Investigación Penal Preparatoria & Juicio & Ejecución \\
\hline Imputativa (art. 274 CPP) & $\begin{array}{l}\text { Audiencia de debate } \\
\text { (arts. } 307 \text { y ss. CPP) }\end{array}$ & Libertad Asistida \\
\hline Prisión Preventiva (art. 223 y 223 CPP) & Salidas transitorias \\
\hline Revisión de prisión preventiva (art. 225 CPP) & Libertad condicional \\
\hline Constitución de querellante (arts. 93 y 99 CPP) & Sanciones disciplinarias \\
\hline Anticipo jurisdiccional de prueba (art. 298 CPP) & Revisiones / \\
mayoritariamente cámara gesell & Flexibilizaciones \\
\hline Procedimiento abreviado & \\
\hline Suspensión de procedimiento a prueba & \\
\hline Preliminar (art. 295 CPP) & \\
\hline
\end{tabular}

Fuente: elaboración propia en base al CPP.

\section{9 el CASO: LAS OFICINA de GESTIÓN JUdiCIAL DEL DISTRITO JUDICIAL N ${ }^{\circ} 1$ Y 2}

El estudio se realizó sobre las oficinas de gestión judicial de primera instancia de los distritos judiciales $\mathrm{N}^{\circ} 1$ - Santa Fe- y $\mathrm{N}^{\circ} 2$ - Rosario. Ambas fueron escogidas ya que en forma conjunta dan servicio al $61,54 \%$ del total de la población santafesina. En lo relativo a los recursos humanos, en comparación con el resto de las oficinas del poder judicial santafesino, estas dependencias del fuero penal poseen alta concentración de personal. En materia de recursos materiales y tecnológicos se instalaron, de acuerdo a informe de la institución (Poder Judicial Santa Fe: 2016), en toda la provincia un total de 41 salas de audiencias, lo que implica que en las dependencias de primera instancia de Santa Fe y Rosario con 6 y 10 salas, respectivamente, poseen aproximadamente el $40 \%$ del total de las salas, lo cual se incrementa cuando se observa que ambas oficinas demandan de manera corriente la utilización de salas "compartidas" de las de segunda instancia.

Los dos distritos judiciales fueron estudiados en relación a las siguientes recursos o factores de producción, medibles cuantitativamente ${ }^{8}: 1$ ) recursos humanos, 2) salas de audiencias y 3) audiencias celebradas. 
Complementariamente a los datos relevados, y de entrevistas realizadas en ambas sedes judiciales a los directores, se pudo determinar que el personal cumple un total de 6 (seis) horas de trabajo diario de lunes a viernes, dividiendo la jornada en matutina de 7 a 13 hs. donde se concentra la mayor cuantía de recursos y vespertina de 13 a 19 hs. - en Rosario-y de 14 a 20 hs. —en Santa $\mathrm{Fe}-$, remarcando que quienes asisten en una franja horaria no lo hace en la otra.

Asimismo, se conforman grupos de trabajo de turno, compuesto por empleados, funcionarios y magistrados, para realizar labores los fines de semana y feriados, concentrándose las actividades en el horario matutino. Los directores han manifestado que en ambas sedes se trabaja los 365 días del año en el desarrollo de audiencias, siendo los fines de semana y feriado sólo audiencias de urgencias.

Las jornadas de trabajo así cumplimentada no aportaría alteraciones a nuestro análisis, ya que ambas sedes desarrollan sus actividades de manera homogénea, y el esfuerzo a emprender para profundizar en el tema, excedería a las necesidades de este trabajo. Desplegaremos a continuación el estudio cuantitativo de los recursos enumerados y será mediante tal abordaje que analizaremos el comportamiento del sistema de producción de audiencias.

\subsection{DISTRITO JUDICIAL N 1 - SANTA FE}

Uniendo en un análisis integral los datos colectados en nuestro trabajo, y recordando que como "producto" de nuestro proceso penal son las «audiencias celebradas", para el caso del distrito judicial $n^{\circ} 1$, observando los datos volcados en la Tabla 5, aclarando que consideramos como días laborables un total de 231 días $^{9}$, pudiendo inferir lo siguiente (ver Tabla 5).

En forma separada exponemos la evolución de los juicios orales realizados, los cuales no son integrados en la tabla anterior, por la ausencia de representatividad en los valores de incidencia de los factores medidos (Gráfico 4). 
Tabla 5.

Incidencias Cantidad de audiencias por juez, E/F, sala en OGJ distrito judicial $N^{\circ} 1$

\begin{tabular}{l|r|rr|rr|rr}
\hline \multirow{2}{*}{ Período } & \multirow{2}{*}{ Audiencias } & \multicolumn{2}{|c|}{ Incidencia por juez } & \multicolumn{2}{c}{ Incidencia Emp. Func. } & \multicolumn{2}{c}{ Incidencia por sala } \\
\hline & & Cant. & Por juez & Cant. & Por E/F & Cant. & Por sala \\
\cline { 3 - 7 } 2014 & 2125 & 6 & 354 & 8 & 265 & 4 & 531 \\
2015 & 2523 & 6 & 420 & 19 & 132 & 4 & 630 \\
2016 & 3453 & 8 & 431 & 24 & 143 & 4 & 863 \\
2017 & 4509 & 9 & 501 & 33 & 136 & 4 & 1127 \\
2018 & 4651 & 16 & 290 & 54 & 86 & 4 & 1162 \\
\hline
\end{tabular}

Fuente: elaboración propia.

\section{Gráfico 4.}

Juicios orales distrito judicial $\mathrm{N}^{\circ} 1$

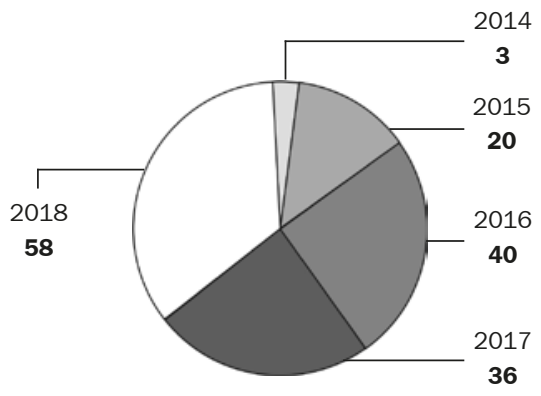

I) La incidencia de cada juez sobre el producido total de audiencias tuvo una etapa positiva en el período 2014-2017, mas en el último año analizado se denota una merma significativa, ya que la incorporación de 7 nuevos jueces en el año 2018 no habría potenciado el número total de audiencias, sino que por el contrario se observó una disminución en la incidencia de cada juez al conjunto del sistema, vale decir se obtuvo una productividad media menor ante el incremento de magistrados. Hipotéticamente 16 jueces a una incidencia igual al año 2017, es decir 501 audiencia por juez, debería de haber aportado una productividad total igual a 8.016 audiencias, lejanos en un $72 \%$ de las 4.651 efectivamente realizadas. 
Es de destacar que, el número de juicios orales desarrollados durante el año 2018 fue de 31, esto ha marcado una sensible influencia en la labor de los magistrados ya que cada juicio al involucrar un promedio de 5 días hábiles de audiencias ${ }^{10}$, los limita de participar de otro tipo de audiencias y se los excluye de la actividad jurisdiccional diferente al juicio en la cual participa. En el mismo sentido, la composición de tribunales pluripersonales lleva a que 3 jueces en forma simultánea se encuentren involucrados por cada juicio oral durante el período de días hábiles indicado. Se inferiría que la mayor cuantía de magistrados, manteniendo en condiciones de ceteris paribus al resto de los recursos, posibilitó un mayor número de juicios orales, así mismo este último hecho podría haber traído aparejado un menor número de audiencias de otro tipo.

II) En cuanto a la labor de gestión de las audiencias (presentación de la solicitud, su agendamiento, su notificación, el desarrollo de la propia audiencia, y las comunicaciones de su resultado), el crecimiento continuo en la cantidad de empleados y funcionarios durante todo el período, no tuvo un impactó proporcional en el número final de audiencias celebradas, así la productividad media de ellos fue permanentemente en disminución, no obstante remarcar que existió un incremento en el nivel general de audiencias realizadas. Hipotéticamente 54 empleados-funcionarios a una productividad media igual al 2017, es decir 136 audiencias, tuviese que haber representado la realización de 7.344 , muy lejos de las 4.651 audiencias efectivamente realizadas en el 2018. El número de juicios en el último período analizado fue sustancialmente mayor, pudiendo indicar, si sólo observamos este recurso, que la designación de un mayor número de empleados-funcionarios tuvo consecuencias positivas en este punto.

III) Un hecho significativo es el tema salas de audiencia. Es claro que aun cuando se haya mantenido estable la cantidad de salas, ello no impidió que se realizara un mayor número de audiencias. Igualmente no se podría realizar ninguna hipótesis de productividad media comparada, ya que el número de salas, en esta oficina, fue el mismo durante todos los períodos considerados. Sí se podría deducir, con los datos relevados, que hubo, durante los primeros 3 años, una notoria subutilización del recurso sala, esto es así ya que la productividad media de cada sala fue permanentemente en aumento.

IV) En líneas generales, se podría decir que, la designación de un número mayor de jueces, empleados y funcionarios, ha tenido una incidencia positiva 
en la cantidad total de audiencias realizadas. En términos del modelo productivista planteado se obtuvo, año a año, una cantidad mayor del producto final.

Reflexionando de una manera estrictamente cuantitativa, la magnitud de la incidencia individual de cada uno de los recursos analizados, manteniendo constante la cuantía del resto de los factores, sería inferior a la productividad óptima, situación que se degrada aún más de acuerdo pasan los años. Inferiríamos de esta manera el cumplimiento del enunciado de la ley de rendimientos decrecientes de los factores.

\subsection{DISTRITO JUDICIAL N 2 - ROSARIO}

Tomando como base de análisis la cantidad de audiencias efectivamente celebradas en el ámbito del distrito judicial $\mathrm{N}^{\circ} 2$, siguiendo los datos volcados en la Tabla 6 y considerando como días laborables un total de 231 días, se puede inferir lo siguiente (ver Tabla 6).

A continuación y en forma separada, exponemos la evolución de los juicios orales realizados, por los motivos expresados anteriormente (Gráfico 5).

\section{Tabla 6}

Incidencias Cantidad de audiencias por juez, E/F, sala en OGJ distrito judicial $\mathrm{N}^{\circ} 2$

\begin{tabular}{|c|c|c|c|c|c|c|c|}
\hline \multirow[t]{2}{*}{ Período } & \multirow[t]{2}{*}{ Audiencias } & \multicolumn{2}{|c|}{ Incidencia por juez } & \multicolumn{2}{|c|}{ Incidencia Emp. Func. } & \multicolumn{2}{|c|}{ Incidencia por sala } \\
\hline & & Cant. & Por juez & Cant. & Por E/F & Cant. & Por sala \\
\hline 2014 & 3425 & 10 & 342 & 31 & 110 & 9 & 380 \\
\hline 2015 & 5142 & $15\left(^{*}\right)$ & 142 & 41 & 125 & 9 & 571 \\
\hline 2016 & 6946 & $17\left(^{*}\right)$ & 408 & 59 & 117 & 12 & 578 \\
\hline 2017 & 7417 & $18\left(^{*}\right)$ & 412 & 63 & 117 & 12 & 618 \\
\hline 2018 & 9294 & $26\left(^{*}\right)$ & 357 & 101 & 92 & $11\left(^{*}\right)$ & 844 \\
\hline
\end{tabular}

${ }^{*}$ ) En todos los casos se promedió entre los totales existentes en el primer semestre y el segundo. Fuente: elaboración propia. 


\section{Gráfico 5.}

Juicios orales distrito judicial $N^{\circ} 2$

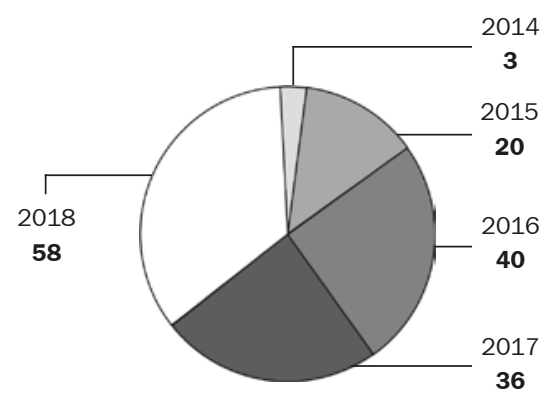

I) La incidencia de la dotación de un mayor número de magistrados en relación a la cantidad de audiencias celebradas nos posibilita observar que, en el año 2015 comparado con el año anterior, fue mayor el número total de audiencias, más la productividad media de cada magistrado fue notablemente inferior en el mismo período. Situación similar se presentó en el año 2018 en relación al 2017. Esto nos podría indicar que existe un impacto positivo en la cantidad total de audiencias efectivamente celebradas, no obstante la participación individual de cada magistrado es sensiblemente menor a la situación anterior. Hipotéticamente 26 jueces a una incidencia igual al año 2017, es decir 412 audiencia individualmente, debería de haber aportado una productividad total igual a 10.712 audiencias, distante en un $10 \%$ de las 9.294 efectivamente realizadas.

Quizás el número de juicios orales desarrollados durante el año 2018 (recordemos un total de 58) ha marcado una sensible influencia en la labor de los magistrados, durante dicho período, ya que cada juicio al involucrar un promedio de 5 días hábiles de audiencias, los limita de participar de otro tipo de audiencias e incluso de actividad jurisdiccional diferente al mismo juicio. En idéntico sentido, la existencia de tribunales pluripersonales lleva a que 3 jueces en forma simultánea se encuentren involucrados por cada juicio oral durante el período de días hábiles indicado. Se infiere que la mayor cuantía de magistrados, con el resto de los recursos constantes, posibilitó un mayor número de juicios orales.

II) En cuanto a la labor de gestión de las audiencias, tarea indelegable de la oficina de gestión judicial, el crecimiento continuo en la cantidad de empleados y funcionarios durante todo los período observados, no tuvo un impactó proporcional en el número final de audiencias celebradas, así la productividad 
media de ellos fue permanentemente en disminución, no obstante remarcar que existió un incremento a nivel general de audiencias realizadas. Se podría expresar que existió una productividad media positiva de cada empleado, pero menor a la situación de años anteriores, siendo notorio entre los años 2017 con 110 audiencias por empleado/funcionario, contra un 2018 con 92, por lo que el número total de audiencias celebradas podría haber sido superior, en caso de continuarse con la productividad media del año 2017. El número de juicios en el último período analizado fue sustancialmente mayor, pudiendo indicar, si sólo nos centramos en este recurso, que la designación de un mayor número de empleados-funcionarios tuvo consecuencias positivas para este tipo de actividad.

III) Un hecho que puede resultar significativo es, el tema salas de audiencia. Es claro que aún cuando se haya mantenido estable la cantidad de salas durante los períodos 2014-2015 y 2016-2017 y disminuido en el 2018, ello no impidió que se realizara un mayor número de audiencias. Se podría realizar una hipótesis de productividad media comparada entre las salas del mismo distrito, lo cual referiría que existió una notoria subutilización del recurso sala durante los períodos anteriores al 2018.

IV) En líneas generales, se podría decir que, la designación de un número mayor de jueces, empleados y funcionarios, y de salas, ha tenido una incidencia positiva en el número total de audiencias celebradas, en nuestro modelo productivista se traduce en el desarrollo de una cantidad mayor del producto final obtenido. Sin embargo, existiría evidencia cuantitativa para considerar que la magnitud de la incidencia individual de cada factor, sería inferior a la productividad óptima, la cual se degrada año a año, considerando constante el resto de los factores. Inferiríamos, al igual que lo hemos hecho en la sede Santa Fe, que de esta manera se cumple con el enunciado de la ley de rendimientos decrecientes de los factores

\section{0 cONSIDERACIONES FINALES}

El campo teórico, nos anticipó tempranamente que existiría un impacto positivo en los resultados globales a alcanzar, a una dotación mayor de recursos, principalmente los humanos. De manera complementaria, mediante la visión productivista, observamos que una dotación mayor de los magistrados, funcionarios, empleados y salas de audiencias — nuestros factores de producción—, genera 
un aumento proporcional en la producción total de audiencias celebradas, dentro de las oficinas de gestión judicial de primera instancia de Santa Fe y Rosario.

En el modelo de producción planteado, también participa el marco legal que le dio forma a la nueva área administrativa del fuero penal, separándola de las funciones del área jurisdiccional, generando las bases de funcionamiento de cada uno y la forma de vincularse entre las mismas. Para ello, la legislatura provincial partiendo de la sanción del código procesal penal, dio comienzo a un compendio de normas que fueron estableciendo formas de realizar la transición entre los dos sistemas penales, el traspaso del personal y la conformación de la oficina de gestión judicial. En el mismo sentido, la corte suprema de justicia reglamentó la estructura que las oficinas tendrían a lo largo de la provincia, dotándola de su organización interna.

Luego de establecer el diagrama normativo, se comenzó con la dotación del resto de los recursos, así principalmente para nuestro estudio se relevaron los recursos humanos y las salas de audiencias. La corte dispuso un número de recursos mínimos, vale decir los factores de producción con los que contarían estas oficinas, con los cuales dar inicio a las labores del fuero. Año a año se fueron dotando de un número mayor de recursos. En lo particular la sede Rosario, recibió en términos absolutos un número superior a la sede Santa Fe.

Ambas sedes, y realizando comparaciones cuantitativas anuales, evidenciaron que una dotación mayor de empleados y funcionarios, si bien habría posibilitado llevar adelante un mayor número total de audiencias celebradas, la producción media de cada nuevo empleado y funcionario fue menor a los años anteriores, ceteris paribus del resto de los factores. Ahora bien, comparando ambas sedes, la producción media de cada empleado y funcionario, fue mayor en la sede Santa Fe $(265,132,143,136$ y 86), por sobre la de Rosario (110, $125,117,117$ y 92), salvo el último año, resultando sustancialmente notorio el primer período. Esto nos indicaría, al menos hasta involucrar en el análisis otras variables cualitativas, que la sede Santa Fe tuvo una productividad media mayor por empleado y funcionario que su par de la sede Rosario.

Cuando se analizó el comportamiento del recurso magistrado, aquí en ambas sedes se observó en el período 2018, que la productividad media de los nuevos jueces es menor al período anterior (a excepción del año 2015 en sede Rosario), ya que ante el ingreso anual de nuevos integrantes del colegio la cantidad promedio de audiencias por juez fue inferior a la situación anterior. Comparando ambas sedes, Santa Fe (354, 420, 431, 501 y 290) y Rosario $(342,142,408,412$ y 357), vemos, hasta no obtener información por intermedio del análisis de variables cualitativas, que al igual que los empleados y 
funcionarios, la sede Santa Fe tuvo una productividad mayor a la sede Rosario, siendo el 2015 y 2017 llamativamente superior, revirtiéndose la tendencia únicamente en el último período estudiado.

El análisis de las salas de audiencias, como recurso de infraestructura con las que fueron dotadas las oficinas de gestión judicial, en la sede Santa Fe, nos deja poco margen de análisis al no haberse incrementado a lo largo de todo el período la cantidad de las mismas, y para el caso de la sede Rosario una mayor dotación de salas permitió un número mayor de audiencias y, además, la productividad media de cada sala fue mayor año a año, no evidenciando disminución como en los casos del resto de los factores de producción observados. Así mismo, en un análisis comparativo la sede Santa Fe (531, 630, 863, 1127 y 1162) evidencia una mayor productividad media en todos los años en relación a la sede Rosario (380, 571, 578, 618 y 844), en lo que a este factor de producción respecta.

Sin ser contundentes, inicialmente y hasta tanto se incluyan otras variables en el análisis o se profundice con un estudio multivariable, podemos mencionar que existirían evidencias que nos permiten observar el cumplimiento de la ley de rendimientos decrecientes de los factores de producción empleados-funcionarios y jueces, no así en el factor sala.

Presentada así la información, se puede destacar que, en términos de audiencias totales celebradas — situación similar se comprobó en el tema de juicios orales-, si bien la sede Rosario (3425, 5142, 6946, 7417 y 9294) posee una labor en términos absolutos superior a la sede Santa Fe (2125, 2523, 3453, 4509 y 4651), para la obtención de dicho resultado se requirió que paralelamente se dote a la sede Rosario de mayores recursos en comparación a la sede Santa $\mathrm{Fe}$, tanto humanos como de infraestructura, tal como surgió del relevamiento efectuado, hablando siempre en términos absolutos.

Complementariamente se ha detectado que, en cada uno de los factores de producción analizados se puede inferir que, la sede Santa Fe fue comparativamente superior a la sede Rosario en términos de productividad media, ya que ante cada incorporación de magistrados, empleados/funcionarios y sala, en Santa Fe se obtuvieron productividades media superiores a las observadas en Rosario, vale remarcar, en la sede Santa Fe se obtuvo un mayor número de audiencias por cada nuevo recurso incorporado, lo que nos estaría indicando una mayor eficiencia en comparación con la sede Rosario, al menos hasta cruzar dicha información con otras variables.

Consideramos conveniente un análisis en profundidad de factores cualitativos (formación, antigüedad, edad para el caso del personal) de los recursos incorporados a las oficinas de gestión judicial, que pudieran incidir en el rendimiento 
individual de los mismos, o profundizar más en el análisis utilizando la teoría de la productividad marginal de los factores de producción, esto último a los fines de determinar el momento a partir del cual la incorporación de un nuevo factor representa una productividad marginal negativa (por ejemplo la cantidad de jueces a partir de la cual es innecesario una nueva incorporación, por no contar con las salas de audiencias disponibles para producir una nueva audiencia).

Los aportes realizados esperamos siva de insumo para la administración de servicio de justicia, específicamente en lo relativo a la materia penal y que sus operadores encuentren en la información expuesta material suficiente para vislumbrar mejoras en la organización, potenciando el resultado final del fuero penal.

La respuesta a parte de nuestro interrogante inicial, que planteaba si una mayor dotación de recursos — humanos e infraestructura — traería aparejado un mayor número de audiencias totales celebradas, encontró a lo largo del trabajo resultados cuantitativos que posibilitaron extraer ilaciones puntuales.

El proceso nos deja resultados que utilizaremos como base para nuestro próximo abordaje, relacionado al presente pero ampliado a nivel nacional, que nos ayudará a generar mayor información para el sector justicia y que potencien las labores que tiendan a un mejor senvicio de justicia dentro del fuero penal.

\section{NOTAS}

${ }^{1}$ Si bien este autor no es el único que realiza un abordaje del funcionamiento del Estado desde una visión productivista, emplearemos su línea de análisis como guía en el presente trabajo, por ser referente en la temática.

2 No siendo este un tratado sobre temas económicos, se invita al lector, si así lo desea, a consultar la amplia bibliografía, que existe sobre los temas de productividad aquí mencionados.

${ }^{3} \mathrm{~A}$ lo largo del presente trabajo se utilizarán como sinónimo, más allá de no desconocer sutilezas de la dogmática que intentan distanciar los términos. Otro vocablo utilizado para referenciar a este sistema es el de "contradictorio", el cual se encuentra más alejado de los anteriores. No obstante, es ampliamente aceptado el uso indistinto de estos términos, incluso en las esferas del derecho.

${ }^{4}$ Citando la obra del profesor Maier, se intenta reflejar la vigencia de sus conceptos, aun cuando la misma fue desarrollada en etapa liminar del diseño de los sistemas adversariales de la región latinoamericana.

5 En el caso de la provincia de Santa Fe, para el fuero penal, estos administradores son profesionales formados en las ciencias económicas o ingenierías.

${ }^{6}$ Existen controversias de cómo se debe proceder a contar el plazo total dado por la norma, escapando a los fines de estudio del presente por ser materia jurídica específica.

${ }^{7}$ No se incorpora en este trabajo un tratamiento de los colegios de jueces de 2 da. Instancia por no tener relevancia sustancial para el estudio realizado aquí.

8 La recolección de información fue realizada por año calendario, sin determinarse el momento del año en que se produjo la incorporación del personal respectivo, ello aplica tanto para empleados, funcionarios y magistrados y sala de audiencias. 9 El número 231 surge de contabilizar un total 
aproximado de 22 días hábiles mensuales, multiplicado por 10 meses y $1 / 2$, excluyendo Enero y 15 días de Julio donde el Poder Judicial tiene su feria judicial. En este sentido, es necesario remarcar que, las oficinas de gestión judicial de toda la provincia prestan funciones ininterrumpida, realizando audiencias los días inhábiles incluido el período de ferias judiciales, por lo que a los fines de poder obtener datos comparativos válidos, se eligió integrar y promediar la cantidad de audiencias en días hábiles.

${ }^{10}$ Alegatos de apertura y testimoniales distribuidos en 2 jornadas, más 1 jornada de alegatos finales, 2 días hábiles para deliberación del tribunal y una jornada final de lectura de fallo, totalizando 5 días hábiles.

\section{BIBLIOGRAFİA}

Binder, A. (2013). La implementación de la nueva justicia penal adversarial. Argentina: ed. AD-HOC.

CEJA (2010). Reformas de la Justicia en América Latina: Experiencias de Innovación, Cap. "La Reforma procesal penal en Chubut: Implementación de una nueva gestión judicial", ed. CEJA, Santiago de Chile, pp. 93-232, disponible en http://www.pensamientopenal.com.ar/ system/files/2014/12/doctrina34125.pdf, (consultado 08/04/2019).

CENSO (2010). https://www.santafe.gov.ar/index.php/web/Estructura-de-Gobierno/Ministerios/ Economia/Secretaria-de-Planificacion-y-Politica-Economica/Direccion-Provincial-del-InstitutoProvincial-de-Estadistica-y-Censos-de-la-Provincia-de-Santa-Fe/ESTADISTICAS/Censos/Poblacion/Censo-Nacional-de-Poblacion-y-Vivienda-2010/Estadisticas-por-Dpto.-y-Pcia/Poblacion/ Poblacion-segun-Censo-Nacional-de-Poblacion-2010.-Provincia-Santa-Fe

Estadísticas del Poder Judicial de Santa Fe, Año 2018 (2018). disponible en: http://www. justiciasantafe.gov.ar/ESTADISTICAS/2018/4.7.19/IV-1-3-\%20Causas\%20ingresadas\%20 por\%20circ\%20y\%20fuero-2018.pdf, (consultado 05/09/2019).

Isuani, F. (2012). «Instrumentos de políticas públicas. Factores claves de las capacidades estatales", DAAPGE, vol. 12, № 19, pp 51-74, UNL, Santa Fe, Argentina.

Langer, M. (2009). Revolución en el Proceso Penal Latinoamericano, en Yomha, Diego G. y Martinez, Santiago M. —coords.— (2009): El Proceso Penal Adversarial: lineamientos para la reforma del sistema judicial, en Revista de Derecho Procesal Penal, Tomo II, $1^{\circ}$ edición, ed. Rubinzal-Culzoni, Santa Fe, pp. 53 a 134.

Las Heras, J.M. (2006). Estado Eficaz. 2da. Ed. Buenos Aires: Ed. Buyatti.

(2018). «Estado Eficiente. Administración financiera gubernamental. Un enfoque sistémico desde una visión de producción", 4ta. Ed. Buenos Aires: Ed. Buyatti.

Longo Gasser, José Luis. La transformación de la cultura organizacional del fuero penal durante el proceso de cambio hacia un sistema adversarial. Tesis (Magister en Administración Púbica). Santa Fe, Argentina. Universidad Nacional del Litoral, Facultad de Ciencias Económicas. 2018. 160p. 
Maier; J. (1996). «Derecho Procesal Penal. Tomo I: Fundamentos. Chile: Ed. del Puerto.

Oszlak, 0. (1972). Diagnóstico de la Administración Pública Uruguaya, en Naciones Unidas, PNUD. Informe Técnico No DP/SF/UN/75, Nueva York.

(2002). Profesionalización de la Función Pública en el marco de la Nueva Gestión Pública, Trabajo presentado en la IV Reunión de Ministros de la Administración Pública y Reforma del Estado, Santo Domingo, República Dominicana, Junio 27-28, 2002. Publicado en Arellano, David (et. Al.) (2003): Retos de la profesionalización de la función pública, CLAD, AECI/MAP/FIIAPP, Venezuela, en http://www.oscaroszlak.org.ar/images/articulos-espanol/ prof\%20de\%20la\%20\%20func\%20pub\%20en\%20el\%20marc\%20de\%20la\%20nue\%20 gest\%20pub.pdf, (consultado 19/11/2018).

(2004). Transformación Estatal y Gobernabilidad en el contexto de la Globalización: Un análisis comparativo de Argentina, Brasil, Chile y Uruguay: el caso Argentino" en http://www. cedes.org/publicaciones/documentos/GestPub/2004/6791.pdf, (consultado 07/08/2018).

(2014). "Políticas Públicas y Capacidades Estatales», Forjando, año 3, número 5. Número especial: Las políticas públicas en la provincia de Buenos Aires, en http://www.oscaroszlak.org.ar/images/articulos-espanol/politicas\%20publicas.pdf (consultado 06/08/2018).

Palma, J.M. (2017). Modernización Judicial, Gestión y Administración en América Latina, Revista Acta Sociológica, № 72, Enero-Abril 2017, pp. 149-203. En https://papers.ssrn.com/ sol3/papers.cfm?abstract_id=2941960, (consultado 13/08/2020).

Poder Judicial de la provincia de Santa Fe, Corte Suprema de Justicia (2016). Diagnóstico-Memoria-Informe, disponible en http://www.justiciasantafe.gov.ar/ESTADISTICAS/ memoria_dianostic_\%20informe_iv_edicion.pdf, (consultado 05/09/2019).

PNUD (2008). "Las capacidades del Estado y las demandas ciudadanas. Condiciones políticas para la igualdad de derechos». Informe PNUD, Argentina.

Rosas Huerta, A. (2008). Una Ruta Metológica para evaluar la Capacidad Institucional, en Política y Cultura, otoño 2008, núm. 30, pp. 119-134, México.

Yardín, A. (2019). El Análisis Marginal: La mejor herramienta para tomar decisiones en mercados competitivos. 4ta. Ed. Argentina: Ed. Buyatti.

\section{PARA CITAR ESTE ARTÍCULO:}

Longo Gasser, J.L. (2020). «El servicio de justicia penal santafesino: producción de audiencias orales, marco jurídico y organización: el caso de la oficina de gestión judicial de los distritos judiciales n 1 y 2", DAAPGE, año 20, № 34 (ene-jun), 2020, pp. 103-138. Santa Fe, Argentina: UNL. 